\title{
Pengetahuan Profesi Tenaga Kefarmasian Terhadap Terapi dan Rawat Luka Pasien Kanker
}

Dinda Monika Nusantara Ratri $^{\star 1,2}$, Mareta Rindang Andarsari, ${ }^{1,2}$, Pharmasinta Putri Hapsari ${ }^{1}$, Marcha Debby Saraswati ${ }^{3}$, Yudistira Nurrizky Grahitaning Putra Rohmaana ${ }^{3}$, Didik Hasmono ${ }^{1}$, Budi Suprapti ${ }^{1,2}$

${ }^{1}$ Departemen Farmasi Praktis, Fakultas Farmasi, Universitas Airlangga, Jawa Timur, Indonesia

2 Departemen Farmasi, Rumah Sakit Universitas Airlangga, Jawa Timur, Indonesia

${ }^{3}$ Program Magister Farmasi Klinik, Fakultas Farmasi, Universitas Airlangga, Jawa Timur, Indonesia

*Email: dindamonika@ff.unair.ac.id

Orchid ID : 0000-0001-6493-3561

(Submit 19/12/2021, Revisi 20/12/2021, Diterima 30/12/2021, Terbit 31/12/2021)

\section{Abstrak}

Penderita kanker dengan modalitas terapi kanker dapat mengalami efek samping obat dan luka kanker. Penyelesaian permasalahan dan peningkatan faktor keselamatan pasien terkait penggunaan obat, serta kualitas hidup yang membaik dipengaruhi oleh kerjasama antara tenaga kesehatan, salah satunya tenaga kesehatan farmasi. Pengetahuan tenaga kefarmasian terkait pengobatan dan perawatan yang diberikan pada pasien kanker sangat dibutuhkan untuk menunjang praktek kolaborasi. Tingkat pengetahuan tenaga kefarmasian penting diketahui untuk upaya penguatan sistem pelayanan kesehatan. Penelitian ini bertujuan untuk mengetahui pengetahuan tenaga kesehatan farmasi terhadap terapi dan rawat luka pasien kanker. Penelitian ini adalah penelitian prospektif, cross-sectional dengan metode non-random sampling. Penelitian dilakukan pada bulan November 2020, pengumpulan data menggunakan survei online. Total 99 orang tenaga kefarmasian yang terdiri dari apoteker dan tenaga teknis kefarmasian mengisi kuesioner tersebut. Selanjutnya dilakukan penilaian pengetahuan pada setiap butir pertanyaan. Sejumlah $71,72 \%$ tenaga kefarmasian memiliki pengetahuan yang baik terhadap hal umum terkait terapi dan rawat luka kanker. Lebih dari sembilan puluh persen tenaga kefarmasian dapat menjawab dengan tepat terkait tujuan terapi kanker, penanggulangan efek samping obat, dan keadaan yang diperhatikan saat perawatan luka. Apoteker memiliki pengetahuan yang baik sebesar $74,39 \%$ dan tenaga teknis kefarmasian sebesar $58,82 \%$. Tenaga kefarmasian memiliki pengetahuan yang baik terkait perihal dasar terapi kanker dan rawat luka pasien kanker. Apoteker memiliki pengetahuan yang baik terutama perihal efek samping obat dibandingkan tenaga teknis kefarmasian.

Kata kunci: Apoteker, Efek Samping Obat, Kanker, Rawat Luka, Tenaga Kefarmasian 


\section{Pendahuluan}

Perkembangan pasien dengan penyakit kanker semakin meningkat setiap tahunnya di seluruh penjuru dunia. Kanker merupakan salah satu dari lima penyakit tidak menular di Indonesia yang mengalami peningkatan angka kejadian ${ }^{1}$. Kemoterapi merupakan salah satu modalitas terapi yang dapat diberikan pada penyakit keganasan, selain radiasi dan operasi. Namun agen ini bersifat toksik, dan tidak bekerja selektif melawan sel kanker². Tercatat dari publikasi sebelumnya hampir seluruh pasien yang menjalani kemoterapi mengalami Efek Samping Obat (ESO), sekitar 90\% efek samping obat ditemukan pada pemberian obat ini ${ }^{3}$. Selain itu luka kanker juga dialami oleh sekitar $10 \%$ pasien kanker, oleh karena progresivitas penyakit, luka bekas operasi dan luka saat menjalani radioterapi ${ }^{4}$. Efek samping dan luka yang terus timbul menyebabkan pasien mengalami keterbatasan dalam aktifitasnya, turunnya kepercayaan diri bahkan hingga depresi ${ }^{5}$.

Permasalahan yang banyak dirasakan oleh pasien kanker tersebut dapat diminimalisir dengan adanya keterlibatan banyak tenaga kesehatan yang kompeten ${ }^{6}$. Tenaga farmasi dibidang onkologi sangat penting untuk bisa menurunkan kejadian efek samping obat dan meningkatkan kualitas hidup pasien kanker ${ }^{7}$. Tenaga kefarmasian dengan bekal pengetahuan klinik yang baik, membuat pekerjaan farmasi klinik dapat dilakukan dengan maksimal. Oleh karena itu pengetahuan tenaga kefarmasian sangat penting untuk diketahui. Penelitian ini bertujuan untuk mengetahui pengetahuan tenaga kefarmasian terkait terapi kanker dan rawat luka kanker.

\section{Metode}

Penelitian ini dilakukan secara prospektif, cross sectional, non-random sampling dengan melakukan analisis secara deskriptif. Pengetahuan tenaga kefarmasian diambil dari data primer, dengan instrument penelitian berupa kuesioner. Penelitian ini dilakukan pada bulan November 2020. Responden penelitian adalah tenaga kefarmasian yang mengikuti webinar tentang efek samping obat dan perawatan luka kanker. Penyebaran informasi webinar tersebut memanfaatkan media sosial dan media massa digital. Kuesioner dibagikan melalui platform Google Forms.

Kriteria inklusi untuk responden adalah tenaga kefarmasian (apoteker maupun tenaga teknis kefarmasian (TTK)) yang bersedia mengisi kuesioner. Kuesioner berisikan total 10 pertanyaan mengenai terapi kanker, efek samping obat kemoterapi dan penangananya, luka kanker dan pengelolaannya. Tabulasi hasil studi dibagi menjadi tiga kelompok, antara lain: tenaga kefarmasian, apoteker dan TTK. Selanjutnya diberikan penilaian mengenai pengetahuan tenaga kefarmasian, dilakukan dengan cara memberikan nilai pada setiap jawaban benar. Setiap pertanyaan yang dijawab benar oleh responden akan diberikan nilai satu, Rentang nilai yang akan didapatkan oleh responden adalah antara $0-10$. Masing-masing responden dinilai pengetahuannya, kategorisasi pengetahuan kurang diberikan pada responden dengan nilai 0-6. Sedangkan responden dengan nilai 7-10 dikategorikan memiliki pengetahuan baik. Selain itu dilakukan juga penilaian tentang butir pertanyaan yang dapat terjawab tepat oleh responden. Pertanyaan yang dapat dijawab dengan tepat adalah pertanyaan yang 
berhasil di jawab benar oleh minimal $70 \%$ total responden. Pengolahan data akan menampilkan profil pengetahuan tenaga kefarmasian secara umum dan profil pengetahuan dibagi berdasarkan dua kelompok profesi yaitu apoteker dan tenaga teknis kefarmasian.

\section{Hasil}

Penelitian ini diikuti oleh total 99 orang dengan profesi tenaga kefarmasian, dengan proporsi (5:1) yang terdiri dari apoteker 82 orang dan tenaga teknis kefarmasian 17 orang. Karakteristik responden ditampilkan dalam tabel 1. Mayoritas penelitian ini diikuti oleh tenaga kefarmasian berjenis kelamin wanita. Responden penelitian berasal dari seluruh penjuru Indonesia dengan asal daerah terbanyak berasal dari Jawa Timur.

Tabel 1 Karakteristik Responden

\begin{tabular}{lc}
\hline \multicolumn{1}{c}{ Karakteristik } & Prosentase \% $(\mathrm{n}=99)$ \\
\hline Jenis Kelamin & 12,12 \\
Laki-laki & 87,87 \\
Wanita & \\
& \\
Asal Daerah & 43,43 \\
Jawa Timur & 17,17 \\
Jawa Tengah & 14,14 \\
Jawa Barat & 7,07 \\
Sumatra & 18,18 \\
Daerah Lain & \\
* Daerah lain: DI Jakarta, DI Yogyakarta, Kalimantan, Bali \\
- Nusa Tenggara, Sulawesi, dan Papua \\
\hline
\end{tabular}

Pada tabel 2 di ketahui pengetahuan tenaga kefarmasian tentang terapi kanker dan rawat luka pasien kanker. Dari studi ini didapatkan rerata pengetahuan tenaga kefarmasian terkait hal tersebut adalah baik. Prosentase tenaga kefarmasian dengan pengetahuan baik adalah $71,72 \%$. Sedangkan pengetahuan baik untuk apoteker dan tenaga teknis kefarmasian secara berturut - turut $74,39 \%$ dan $58,82 \%$.

Tabel 2 Pengetahuan tenaga kefarmasian tentang terapi kanker dan perawatan luka kanker

\begin{tabular}{lccc}
\hline \multirow{2}{*}{ Pengetahuan } & & Profesi & \\
\cline { 2 - 4 } & & & $\begin{array}{c}\text { Tenaga Teknik } \\
\text { Kefarmasian }\end{array}$ \\
& $\begin{array}{c}\text { Tenaga Kefarmasian* } \\
(\mathrm{n}=99)\end{array}$ & $\begin{array}{c}\text { Apoteker } \\
(\mathrm{n}=82)\end{array}$ & $(\mathrm{n}=17)$ \\
\hline Nilai rata - rata & 7,80 & 7,95 & 7,05 \\
Kategori rata - rata $_{\text {Kurang }^{\dagger}(\%)}^{\text {Baik }}$ & 28,28 & Baik & Baik \\
Baik $^{\ddagger}(\%)$ & 71,72 & 25,61 & 41,18 \\
\hline
\end{tabular}

* Tenaga kefarmasian adalah apoteker dan tenaga teknis kefarmasian; † Pengetahuan kurang dengan nilai 0-6; 
Dari 10 poin pertanyaan yang diberikan pada responden, terdapat empat pertanyaan yang tidak terjawab dengan tepat (tabel 3 ). Pertanyaan yang banyak tidak terjawab dengan tepat oleh tenaga kefarmasian adalah: pencegahan infeksi saat rawat luka $(48,48 \%)$, modalitas terapi kanker $(63,64 \%)$, tahapan rawat luka $(65,66 \%)$, dan ESO kemoterapi $(68,37 \%)$. Dari dua kelompok tenaga kefarmasian, terdapat perbedaan hasil dari pertanyaan yang tidak terjawab tepat antara apoteker dan tenaga teknis kefarmasian yaitu pada poin pertanyaan efek samping obat kemoterapi. Pada kelompok apoteker $74,07 \%$ menjawab pertanyaan dengan tepat, sedangkan pada kelompok tenaga teknis kefarmasian hanya $41,18 \%$ yang menjawab dengan tepat pertanyaan ini.

Tabel 3 Prosentase jawaban benar tenaga kefarmasian tentang terapi kanker dan perawatan luka kanker

\begin{tabular}{|c|c|c|c|}
\hline \multirow{2}{*}{ Pengetahuan } & \multicolumn{3}{|c|}{ Jawaban Benar (\%) } \\
\hline & $\begin{array}{c}\text { Tenaga } \\
\text { Kefarmasian* } \\
(\mathrm{n}=99)\end{array}$ & $\begin{array}{l}\text { Apoteker } \\
(\mathrm{n}=82)\end{array}$ & $\begin{array}{c}\text { Tenaga Teknik } \\
\text { Kefarmasian } \\
(n=17) \\
\end{array}$ \\
\hline Tujuan terapi kanker & 92,93 & 91,46 & 100,00 \\
\hline Modalitas terapi kanker & $63,64^{\dagger}$ & $65,85^{\dagger}$ & $52,94^{\dagger}$ \\
\hline ESO kemoterapi & $68,37^{\dagger}$ & 74,07 & $41,18^{\dagger}$ \\
\hline Penanganan ESO & 77,78 & 79,27 & 70,59 \\
\hline Pengelolaan aktivitas saat mengalami ESO & 96,91 & 96,30 & 100,00 \\
\hline Ciri luka kanker & 84,86 & 85,37 & 82,35 \\
\hline Faktor yang mempengaruhi luka kanker & 85,86 & 87,80 & 76,47 \\
\hline $\begin{array}{l}\text { Kondisi yang diperhatikan saat rawat luka } \\
\text { kanker }\end{array}$ & 97,98 & 98,78 & 94,12 \\
\hline Tahapan perawatan luka kanker & $65,66^{\dagger}$ & $67,07^{\dagger}$ & $58,82^{\dagger}$ \\
\hline $\begin{array}{l}\text { Pencegahan infeksi saat perawatan luka } \\
\text { kanker }\end{array}$ & $48,48^{\dagger}$ & $51,22^{\dagger}$ & $35,29^{\dagger}$ \\
\hline
\end{tabular}

${ }^{*}$ Tenaga kefarmasian adalah apoteker dan tenaga teknis kefarmasian; ${ }^{\dagger}$ Poin pertanyaan yang tidak terjawab dengan tepat

\section{Pembahasan}

Dari hasil studi ini didapatkan tingkat pengetahuan rata-rata terhadap terapi dan rawat luka kanker adalah baik. Hal ini dipengaruhi oleh pengetahuan baik yang dimiliki oleh tenaga farmasis terhadap penyakit kanker ${ }^{8}$. Frekuensi tenaga kefarmasian terlibat dalam penanganan luka sangat minimal, selain itu kebanyakan luka yang dihadapi adalah jenis luka kecil ${ }^{9}$. Pada kasus pasien kanker, luka yang dialami pasien adalah luka keganasan dengan ulserasi ${ }^{10}$. Penanganan luka pada pasien kanker membutuhkan pendekatan yang sistematis dan komprehensif, karena untuk merawat luka ini terdapat beberapa kondisi yang perlu diperhatikan yaitu: pendarahan, bau, nyeri, eksudat, dan infeksi superfisial ${ }^{11}$. Kompetensi seorang apoteker pada pelayanan pasien kanker lebih berfokus dibidang tertentu, antara lain: tindakan professional, kemampuan personal, pengadaan obat kanker, penggunaan obat kanker yang aman dan rasional, ketrampilan manajerial dan organisasi, serta kemampuan dalam promosi kesehatan masyarakat ${ }^{12}$. 
Pada penelitian ini banyak tenaga kefarmasian menjawab salah satu tindakan pencegahan infeksi adalah dengan penggunaan antibiotik topikal. Hal ini dimungkinkan oleh karena adanya studi meta analisis yang menyatakan bahwa penggunaan antibiotik lokal pada pasien operasi dapat menurunkan angka infeksi paska pembedahan ${ }^{13}$. Dari data lain juga menunjukan tindakan pembedahan adalah modalitas terapi terbanyak yang diterima oleh pasien kanker ${ }^{14}$. Pemberian antibiotik topikal biasanya digunakan pada luka kanker yang terdapat infeksi lokal, alih-alih digunakan sebagai tindakan pencegahan ${ }^{11}$.

Tidak terjawabnya pertanyaan mengenai ESO kemoterapi dengan tepat, disebabkan oleh karena responden pada penelitian ini melibatkan dua profesi yang terlibat dalam pekerjaan kefarmasian. Apoteker memiliki tanggung jawab lebih besar dibandingkan dengan TTK untuk melakukan pelayanan kefarmasian, salah satunya adalah dalam bentuk pemantauan ESO. Tidak hanya itu, apoteker juga memiliki sifat yang lebih baik terhadap pelaporan dan tindakan penanganan ESO dibandingkan dengan TTK ${ }^{15}$. Apoteker adalah profesi kesehatan yang memiliki pengetahuan paling baik terkait ESO dibandingkan dengan tenaga kesehatan lainnya ${ }^{16}$. Dari pernyataan diatas dapat diketahui bahwa apoteker memiliki kompetensi lebih terhadap kejadian efek samping karena pengobatan, hal ini mungkin dapat dikarenakan ilmu farmakoterapi dan farmakovigilans sangat lekat terhadap profesi ini.

\section{Kesimpulan}

Dari penelitian ini diketahui bahwa tenaga kefarmasian memiliki pengetahuan yang baik terkait terapi kanker dan rawat luka pasien kanker. Dengan ini pelayanan pasien kanker dapat lebih optimum dengan keterlibatan profesi kefarmasian. Pengetahuan mengenai efek samping obat kemoterapi lebih diketahui oleh apoteker dibandingkan dengan tenaga teknis kefarmasian. Kompetensi apoteker pada efek samping obat dapat bermanfaat untuk pemantauan terapi pasien kanker sehingga meningkatkan keselamatan pasien.

\section{Ucapan Terima Kasih}

Peneliti mengucapkan terima kasih atas partisipasi seluruh staf dosen kelompok berbasis keilmuan farmasi klinik Fakultas Farmasi Universitas Airlangga atas terselenggaranya penelitian ini.

\section{Daftar Pustaka}

1. Biro Komunikasi dan Pelayanan Masyarakat KK. Potret Sehat Indonesia dari Riskesdas 2018 [Internet]. 2018 [cited 2020 Jan 24]. Available from: https://www.depkes.go.id/article/view/18110200003/potret-sehat-indonesia-daririskesdas-2018.html

2. Neal AJ, Hoskin PJ. Cllinical Oncology Basic Principles and Practice. Fourth edi. United Kingdom: CRC Press; 2009. 142-151 p. 
3. Wahlang JB, Laishram PD, Brahma DK, Sarkar C. Adverse drug reactions due to cancer chemotherapy in a tertiary care teaching hospital. Therapeutic Advances in Drug Safety [Internet]. 2017;8(2):61-6. Available from: https://www.ncbi.nlm.nih.gov/pmc/articles/PMC5315222/pdf/10.1177_204209861 6672572.pdf

4. Young T. Caring for patients with malignant and end-of-life wounds. Wounds UK. 2017. p. 20-8.

5. Brien CO. Malignant wounds Managing odour. Canadan Family Physician. 2012;58:272-4.

6. Rosen MA, Diazgranados D, Dietz AS, Benishek LE, Thompson D, Weaver SJ. Teamwork in Healthcare. Teamwork in Healthcare. 2020;73(4):433-50.

7. Tanaka K, Hori A, Tachi T, Osawa T, Nagaya K, Makino T, et al. Impact of pharmacist counseling on reducing instances of adverse events that can affect the quality of life of chemotherapy outpatients with breast Cancer. Journal of Pharmaceutical Health Care and Sciences. 2018;4(1):1-14.

8. Shawahna R, Awawdeh H. Pharmacists' knowledge, attitudes, beliefs, and barriers toward breast cancer health promotion: a cross-sectional study in the Palestinian territories. BMC Health Services Research. 2021;21(1):1-14.

9. Abduelkarem A, Dada M, Sharif S. The provision of wound management services by community pharmacists in Dubai, United Arab Emirates. Jordan Journal of Pharmaceutical Sciences. 2012;5(3):194-202.

10. Artico M, Dante A, D'Angelo D, Lamarca L, Mastroianni C, Petitti T, et al.

Prevalence, incidence and associated factors of pressure ulcers in home palliative care patients: A retrospective chart review. Palliative Medicine [Internet]. 2017 Nov 13;32(1):299-307. Available from: https://doi.org/10.1177/0269216317737671

11. Woo KY, Sibbald RG. Local Wound Care for Malignant and Palliative Wounds. Advance in Skin \& Wound Care. 2010;23(September):417-28.

12. NCCP. Framework for Pharmacists Working in Cancer Care [Internet]. 2015. Available from:

http://www.hse.ie/eng/services/list/5/cancer/profinfo/training/Pharmacist Cancer Care Competency Frameword.pdf\%0Afile://C:/Users/Alan/Documents/Mendeley Desktop/National Cancer Control Programme/Unknown/National Cancer Control Programme - 2015 - Framewor

13. Heal CF, Banks JL, Lepper PD, Kontopantelis E, van Driel ML. Topical antibiotics for preventing surgical site infection in wounds healing by primary intention. Cochrane Database of Systematic Reviews [Internet]. 2016;(11). Available from: https://doi.org//10.1002/14651858.CD011426.pub2 
14. Pangribowo S. Beban Kanker di Indonesia. Pusat Data Dan Informasi Kesehatan Kementerian Kesehatan RI. 2019;1-16.

15. Al-Worafi YM, Kassab YW, Alseragi WM, Almutairi MS, Ahmed A, Ming LC, et al. Pharmacovigilance and adverse drug reaction reporting: A perspective of community pharmacists and pharmacy technicians in Sana'a, Yemen. Therapeutics and Clinical Risk Management. 2017;13:1175-81.

16. Hussain R, Hassali MA, Hashmi F, Akram T. Exploring healthcare professionals' knowledge, attitude, and practices towards pharmacovigilance: a cross-sectional survey. Journal of Pharmaceutical Policy and Practice [Internet]. 2021;14(1):1-13. Available from: https://doi.org/10.1186/s40545-020-00287-3 